\title{
Effect of periapical surgery on oral health-related quality of life in the first postoperative week using the Dutch version of Oral Health Impact Profile-14
}

\author{
Jacco G. Tuk ${ }^{1}$. Jerome A. Lindeboom ${ }^{1}$. Arjen J. van Wijk ${ }^{2}$ \\ Received: 28 October 2020 / Accepted: 21 February 2021 / Published online: 24 March 2021 \\ (c) The Author(s) 2021
}

\begin{abstract}
Objective To evaluate whether periapical surgery affects oral health-related quality of life (OHRQoL) within the first postoperative week.

Study design The primary outcomes in 133 patients (54 men, 79 women; mean age 50.8 years) undergoing periapical surgery were the Oral Health Impact Profile-14 (OHIP-14) score and postoperative sequelae, including pain, analgesic intake, swelling, limited mouth opening, chewing difficulties, and postoperative infection.

Results We found a significant effect on OHIP-14, pain, and analgesics, which decreased throughout the week. We found no significant differences in mean OHIP-14, pain scores, or analgesic use for gender, medical history, surgical flaps, operation time, or location of the operated teeth. Younger patients had a higher OHIP-14 score in the first 2 days after surgery and more pain on the first postoperative day. Women experienced more pain during the first 3 days. Smokers had a higher OHIP-14 score on the first postoperative day and greater pain during the first 3 days compared to non-smokers.

Conclusion We identified a low incidence of pain and reduced OHRQoL following periapical surgery. The postoperative reduction in OHRQoL and pain were of short duration, with maximum intensity in the early postoperative period and rapidly decreasing with time.
\end{abstract}

Keywords Periapical surgery $\cdot$ Pain $\cdot$ OHRQoL

\section{Introduction}

Periapical surgery is a therapeutic surgical procedure to treat teeth with periapical inflammation, particularly when orthograde retreatment is problematic or fails to lead to regression of the apical pathology $[1,2]$. As with any surgery, periapical surgery causes tissue damage and can have both a local and systemic impact that deteriorates the patient's quality of life (QoL). There has been little emphasis on immediate

Jerome A. Lindeboom

j.a.lindeboom@amsterdamumc.nl

1 Departments of Oral and Maxillofacial Surgery, Amsterdam University Medical Center Amsterdam and Amstelland Hospital Amstelveen, Meibergdreef 9, 1105 AZ Amsterdam, The Netherlands

2 Department of Social Dentistry, Academic Centre for Dentistry Amsterdam (ACTA), University of Amsterdam and Vrije Universiteit Amsterdam, Amsterdam, The Netherlands postoperative outcomes, such as pain, swelling, and the patient's well-being after periapical surgery, but the number of studies evaluating the influence on QoL during the period following endodontic surgery is growing [3-17]. In the decision-making process regarding endodontic surgery, clinicians need to consider patients' postoperative discomfort. Pain and swelling are common following periapical surgery, but postoperative pain is reported to be of short

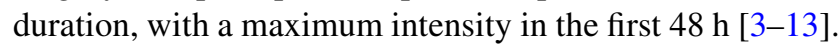
Routine daily activities, function, and loss of work are reported to be only moderately impaired [14]. Several studies have investigated additional interventions to ameliorate the effect of periapical surgery on postoperative pain and QoL [9, 15-17]. The use of corticosteroids has been reported as a pain relief measure in periapical surgery [9], although another study failed to find an effect of submucosal injection of $4 \mathrm{mg}$ dexamethasone on pain, bruising, and wound healing [16]. Conflicting outcomes have also been reported for the use of platelet concentrates in periapical surgery. Del Fabbro et al. [15] found a significant beneficial effect of 
adjunct platelet concentrate on postoperative QoL, whereas a recent study evaluating the impact of adjunct leukocyte and platelet-rich-fibrin on QoL after periapical surgery found no significant improvement during the first postoperative week [15-17].

The aim of the present study was to investigate whether periapical surgery affects oral health-related quality of life (OHRQoL) during the first postoperative week. Patients were surveyed using the Oral Health Impact Profile-14 (OHIP-14) questionnaire. In addition, we assessed postoperative pain, analgesic intake, and infection in the first postoperative week.

\section{Materials and methods}

\section{Patient selection}

Patients referred by their dentists for periapical surgery at the Department of Oral and Maxillofacial Surgery of Amstelland Hospital in Amstelveen, the Netherlands, during 2017 and 2018 were eligible for inclusion in this prospective study. The study was reviewed and approved by the institutional Medical Ethics Committee of the Academic Medical Centre of the University of Amsterdam and conducted in accordance with Good Clinical Practice and the Declaration of Helsinki, as amended in Somerset West, Republic of South Africa, in 1996. Patients were fully informed about the surgical procedure, postoperative care, follow-up examinations, and alternative treatment options. Each patient was informed that they could withdraw from the study at any time without consequences regarding their treatment.

\section{Inclusion and exclusion criteria}

Patients with apical periodontitis in a root canal-treated tooth were included in this study. Asymptomatic patients aged $\geq 18$ years and in good health (American Society of Anesthesiologists (ASA) I or II) who were willing to participate and able to read, understand, and answer the questionnaire were considered for inclusion if they had periapical periodontitis with no possibility of root canal retreatment or the ability to achieve better results with a nonsurgical approach. Patients underwent a clinical and radiographic examination, and a panoramic radiograph and periapical radiograph were taken. The tooth to be treated had to have an adequate final restoration without clinical evidence of coronal leakage. No acute symptoms were present, and the diameter of the periapical lesions had to be $<10 \mathrm{~mm}$ as measured on the periapical radiograph.

Exclusion criteria were other causes related to root pathology other than apical re-infection, such as root fractures, teeth with an inadequate coronal restoration, perforations and bone loss (periodontal pockets deeper than $7 \mathrm{~mm}$ ), and defects of the buccal and lingual cortical bone, as suggested by Zuolo et al. [18]. Other exclusion criteria were antibiotic prophylaxis, a history of a recent and/or symptomatic peptic ulcer, antiplatelet or anticoagulant therapy, pregnancy or lactation, recent ( $<15$ days) acute local infection before surgery, previous radiation therapy to the maxillofacial region, or lack of consent to undergo the procedure or participate in the study.

\section{Surgery}

The surgery was performed by two surgeons (JT and JL). Patients received local anesthesia with $40 \mathrm{mg}$ of articaine/ hydrochloride and $0.01 \mathrm{mg}$ epinephrine (Ultracain D-S Forte, Sanofi-Aventis Netherlands BV, Gouda, the Netherlands). The surgical technique consisted of a midlevel, rectangular or triangular, full-thickness mucoperiosteal flap. The surgical flap was reflected, and bone removed by a round burr with continuous sterile distilled water irrigation to expose the root apex. After debridement of the pathological tissue, the root was resected approximately $3 \mathrm{~mm}$ from the apex using a cylinder burr with minimal or no bevel. Using glasses with 5.0 magnification loupes and a PureLight Headlamp with $140 \mathrm{~mm}$ spot size (SL Company, London, UK), the root end was prepared using ultrasound to a 2-3-mm depth with ultrasonic retrotips (Mectron S.p.A., Carasco, Italy). Intermediate Restorative Material (IRM, Dentsply, Konstanz, Germany) was placed into a dried cavity after adequate hemostasis. Before wound closure, the bone cavity was cleaned with $10 \mathrm{ml}$ of $0.9 \% \mathrm{NaCl}$ solution (B Braun, Melsungen, Germany). The wound was closed by re-approximating the soft tissue to the original position and sutured with Vicryl 4/0 (Johnson and Johnson; Somerville, NJ) before taking final radiographs.

\section{Postoperative instructions}

After surgery, patients were given verbal and written instructions, including information about swelling, using an ice pack for cooling the cheek to reduce swelling and pain relief, avoiding mouth rinsing and spitting, practicing caution when eating and drinking hot food and beverages, and avoiding physical activities. Patients $<50$ years of age with an ASA I classification were prescribed $600 \mathrm{mg}$ ibuprofen (Brufen; Abbot BV, Hoofddorp, the Netherlands) three times a day postoperatively, whereas patients $\geq 50$ years old or with an ASA II classification were prescribed $1000 \mathrm{mg}$ paracetamol 3-4 per day postoperatively. No antibiotics were prescribed. The day after surgery, patients began using a $0.12 \%$ aqueous chlorhexidine mouth rinse twice a day for 1 min for 7 days. Patients were informed to contact the surgeon if they experienced severe pain, swelling, fever, bleeding, or any concerns after surgery. 


\section{Follow-up}

One week after surgery, patients were examined by an independent assessor to assess surgical site wound healing and to check for wound infection. Remaining resorbable sutures were removed. Infection was defined as the presence of purulent discharge and/or excessive swelling with fluctuation, with or without pain; presence of a local abscess; or onset of facial or cervical cellulitis plus other signs suggesting infection, such as pain, increased heat, temperature, erythema, and/or fever [19]. In patients in whom infection was diagnosed, drainage was followed by a 5-day course of amoxicillin three times a day. The number of postoperative visits, type and amount of analgesic, type and dosage of antibiotic, and interventions were documented. The completed OHIP-14 questionnaires and pain scores were collected.

\section{Outcome measurements}

The primary outcome measures were the OHIP-14 questionnaire and pain score based on the numeric rating scale (NRS). Each patient was asked to complete a questionnaire in the first 7 days postoperatively. The questionnaire was translated into Dutch, comprising 14 questions to evaluate the OHRQoL on a 5-point scale ranging from 0 ("never") to 4 ("very often") [20, 21]. Higher scores on the OHIP-14 (range 0-56) indicated a worse OHRQoL. The questionnaire was supplemented with additional questions on analgesic use and postoperative symptoms, such as limited mouth opening, limited chewing, and swelling. The patients were asked to complete the daily OHIP-14 questionnaire, to evaluate pain and analgesic intake at the end of each day. Pain assessment was measured by rating pain intensity with an 11-point NRS, which ranged from 0 (no pain) to 10 (worst possible pain). The daily analgesic intake was self-reported, by filling in the number of used painkillers on each postoperative day.

\section{Data management}

Data were collected and imported into a database. Variables included patient age, gender, medical history, and smoking habits. Age at surgery was computed in years as the difference between the date of operation and the patient's date of birth. Furthermore, the location of the treated tooth, surgical flap design, and operation times were recorded.

\section{Statistical analysis}

Data were analyzed using SPSS version 25 (SPSS Inc., Chicago, IL, USA). Significance was set at $\alpha=0.05$. To obtain the overall mean OHIP-NL14 score, all 14 questions were averaged for each day, and this score was used to compare changes over time and between groups.
Repeated measures ANOVA within subjects was performed to assess the change over time (day 1-7). Additional analyses were conducted to determine the relationship between OHRQoL and the other study variables (age, gender, smoking, ASA classification, and tooth position) over time by means of univariate analysis of variance. Between-group comparisons were performed by means of independent $t$-tests.

\section{Results}

A total of 133 patients (54 (40.6\%) males and $79(59.4 \%)$ females) participated in this study, and all questionnaires were included in the study. The mean patient age was 50.8 years (SD 14.7) for the whole population, 50.7 years (SD 14.8) for the males, and 51 years (SD 14.7) for the females. Surgery was performed in 22 maxillary anterior teeth (16.5\%), 29 maxillary premolars (21.8\%), 37 maxillary molars (27.8\%), 3 mandibular anterior teeth (2.3\%), 5 mandibular premolars (3.8\%), and 37 mandibular molars $(27.8 \%)$.

\section{OHIP-14 scores}

Of the 133 returned questionnaires, the mean overall OHIP14 score was determined for postoperative days 1 to 7 (Table 1). Repeated measures ANOVA was used to analyze the mean overall OHIP-14 scores collected each day during the first postoperative week, indicating a significant effect for the repeated measurements $(\mathrm{F}(6,792)=72.8, p<0.001)$. Subsequent pairwise comparisons indicated that the mean OHIP-14 scores decreased significantly throughout the week. Only the mean scores from day 5 and day 6 did not differ significantly $(p=0.11)$, whereas all the mean scores on the other days differed significantly from each other $(p<0.05)$. No significant differences in mean OHIP-14 scores were found for gender, ASA score, surgical flaps, or operation time. Smokers had a significantly higher OHIP14 score on the first postoperative day than non-smokers. Patients who had a postoperative infection had a significantly higher OHIP-14 score on the fifth postoperative day. Younger patients had a significantly higher OHIP-14 score on the first 2 postoperative days compared to the older patient groups. Figure 1 shows the mean OHIP-14 scores per location. No significant interaction effect between time and OHIP-14 score was found for anterior teeth, premolars, and molars in the upper or lower jaw. Comparing the second molar region with the other locations, no significant differences were found during the week for the mean OHIP14 scores during the first 3 days (day $1, p=0.84$; day 2 , $p=0.34$; day $3, p=0.27$ ). 
Table 1 OHIP-14 scores on postoperative days $1-7$

\begin{tabular}{|c|c|c|c|c|c|c|c|c|c|}
\hline Group & Sample & Mean SD & Day 1 & Day 2 & Day 3 & Day 4 & Day 5 & Day 6 & Day 7 \\
\hline \multirow[t]{2}{*}{ Men } & \multirow[t]{2}{*}{54} & Mean & 11.48 & 8.26 & 6.11 & 5.44 & 4.83 & 3.91 & 3.43 \\
\hline & & SD & 10.31 & 9.34 & 8.59 & 7.71 & 6.22 & 6.63 & 6.37 \\
\hline \multirow[t]{2}{*}{ Women } & \multirow[t]{2}{*}{79} & Mean & 14.47 & 10.86 & 8.35 & 6.97 & 5.20 & 4.28 & 3.61 \\
\hline & & SD & 10.61 & 9.17 & 8.31 & 8.19 & 7.97 & 6.21 & 5.80 \\
\hline \multirow[t]{2}{*}{ ASA I } & \multirow[t]{2}{*}{88} & Mean & 13.63 & 10.01 & 7.52 & 6.75 & 4.78 & 4.43 & 3.97 \\
\hline & & SD & 10.93 & 9.21 & 8.37 & 8.10 & 6.94 & 6.49 & 6.62 \\
\hline \multirow[t]{2}{*}{ ASA II } & \multirow[t]{2}{*}{45} & Mean & 12.53 & 9.40 & 7.29 & 5.58 & 5.58 & 3.53 & 2.69 \\
\hline & & $\mathrm{SD}$ & 9.86 & 9.54 & 8.75 & 7.84 & 7.99 & 6.14 & 4.55 \\
\hline \multirow[t]{2}{*}{ Smokers } & \multirow[t]{2}{*}{17} & Mean & $18.59^{*}$ & 11.76 & 8.12 & 5.88 & 4.82 & 3.35 & 2.47 \\
\hline & & SD & 11.48 & 8.58 & 7.60 & 5.70 & 6.12 & 4.85 & 4.14 \\
\hline \multirow[t]{2}{*}{ Non-smokers } & \multirow[t]{2}{*}{116} & Mean & $12.47 *$ & 9.52 & 7.34 & 6.42 & 5.09 & 4.24 & 3.69 \\
\hline & & SD & 10.23 & 9.39 & 8.61 & 8.31 & 7.47 & 6.57 & 6.24 \\
\hline \multirow[t]{2}{*}{ Age $18-25$ yrs } & \multirow[t]{2}{*}{5} & Mean & $19.20 *$ & $12.00^{*}$ & 9.00 & 10.00 & 0.20 & 2.40 & 1.60 \\
\hline & & $\mathrm{SD}$ & 12.46 & 7.81 & 5.61 & 8.28 & 0.45 & 2.61 & 1.82 \\
\hline \multirow[t]{2}{*}{ Age $26-45$ yrs } & \multirow[t]{2}{*}{45} & Mean & $17.60 *$ & $12.78^{*}$ & 9.91 & 7.91 & 6.67 & 5.71 & 4.89 \\
\hline & & SD & 11.31 & 10.95 & 9.84 & 8.55 & 7.47 & 7.48 & 7.46 \\
\hline \multirow[t]{2}{*}{ Age $46-65$ yrs } & \multirow[t]{2}{*}{61} & Mean & $11.13 *$ & $8.64 *$ & 6.18 & 4.90 & 4.18 & 3.05 & 2.75 \\
\hline & & $\mathrm{SD}$ & 9.24 & 7.90 & 6.86 & 5.99 & 6.87 & 4.95 & 4.85 \\
\hline \multirow[t]{2}{*}{ Age $>65 \mathrm{yrs}$} & \multirow[t]{2}{*}{22} & Mean & $8.91 *$ & $6.55^{*}$ & 5.55 & 6.36 & 5.27 & 4.27 & 3.36 \\
\hline & & $\mathrm{SD}$ & 8.74 & 8.12 & 9.22 & 10.94 & 8.29 & 7.52 & 6.03 \\
\hline \multirow[t]{2}{*}{ Postop infection } & \multirow[t]{2}{*}{7} & Mean & 15.00 & 14.14 & 13.29 & 11.57 & $10.43^{*}$ & 8.00 & 7.43 \\
\hline & & $\mathrm{SD}$ & 14.40 & 14.37 & 11.60 & 6.06 & 3.51 & 4.20 & 5.68 \\
\hline \multirow[t]{2}{*}{ No postop infection } & 126 & Mean & 13.16 & 9.56 & 7.12 & 6.60 & $4.75^{*}$ & 3.91 & 3.32 \\
\hline & & $\mathrm{SD}$ & 10.37 & 8.95 & 8.20 & 8.00 & 7.34 & 6.41 & 5.98 \\
\hline Quadr. flap & 63 & Mean & 13.65 & 10.17 & 8.06 & 6.94 & 5.19 & 4.67 & 4.02 \\
\hline & & SD & 12.01 & 10.70 & 9.31 & 7.99 & 7.21 & 7.06 & 6.80 \\
\hline Triang. flap & 60 & Mean & 12.23 & 8.85 & 6.38 & 5.32 & 4.32 & 3.25 & 2.70 \\
\hline & & SD & 8.31 & 7.10 & 7.12 & 7.62 & 6.54 & 5.39 & 4.43 \\
\hline Midlevel flap & 10 & Mean & 16.90 & 13.20 & 9.90 & 8.90 & 8.60 & 6.00 & 5.50 \\
\hline & & SD & 12.81 & 11.31 & 10.25 & 10.12 & 11.11 & 7.04 & 8.55 \\
\hline Surgery & & & & & & & & & \\
\hline$<20$ min & 63 & Mean & 14.78 & 10.68 & 7.97 & 6.59 & 5.29 & 4.11 & 3.25 \\
\hline & & SD & 10.43 & 10.02 & 9.27 & 8.79 & 7.62 & 5.97 & 5.34 \\
\hline $20-25 \mathrm{~min}$ & 18 & Mean & 12.22 & 8.72 & 6.33 & 5.56 & 5.28 & 4.50 & 4.17 \\
\hline & & $\mathrm{SD}$ & 9.21 & 6.68 & 7.23 & 7.00 & 6.43 & 6.65 & 6.45 \\
\hline 26-30 min & 44 & Mean & 12.63 & 9.55 & 7.72 & 6.84 & 5.23 & 4.41 & 3.84 \\
\hline & & SD & 11.48 & 9.54 & 8.28 & 7.78 & 7.75 & 7.28 & 6.82 \\
\hline$>30 \mathrm{~min}$ & 8 & Mean & 7.00 & 6.75 & 4.25 & 3.63 & 1.75 & 1.88 & 2.63 \\
\hline & & SD & 7.05 & 7.05 & 4.95 & 4.63 & 2.12 & 2.85 & 6.30 \\
\hline Overall & 133 & Mean & 13.26 & 9.80 & 7.44 & 6.35 & 5.05 & 4.13 & 3.53 \\
\hline & & SD & 10.55 & 9.87 & 8.47 & 8.00 & 7.29 & 6.37 & 6.01 \\
\hline
\end{tabular}

quadr quadrangular; triang triangular; $S D$ standard deviation ${ }^{*} p<0.05$

\section{Pain scores}

Repeated measures were used to determine mean scores over time for pain from postoperative days 1 to 7. Repeated measures ANOVA was used to analyze mean NRS scores collected each day during the first postoperative week (Table 2). We found a significant effect for the repeated measurements $(\mathrm{F}(6,792)=61.3$, $p<0.001)$. Subsequent pairwise comparisons showed that the mean NRS scores decrease significantly throughout the week. Only the mean scores from day 3 and day 4 did not differ significantly ( $p=0.15)$, whereas all the mean 
Fig. 1 Mean OHIP-14 score per location during the 1st postoperative week. Error bars indicate SD

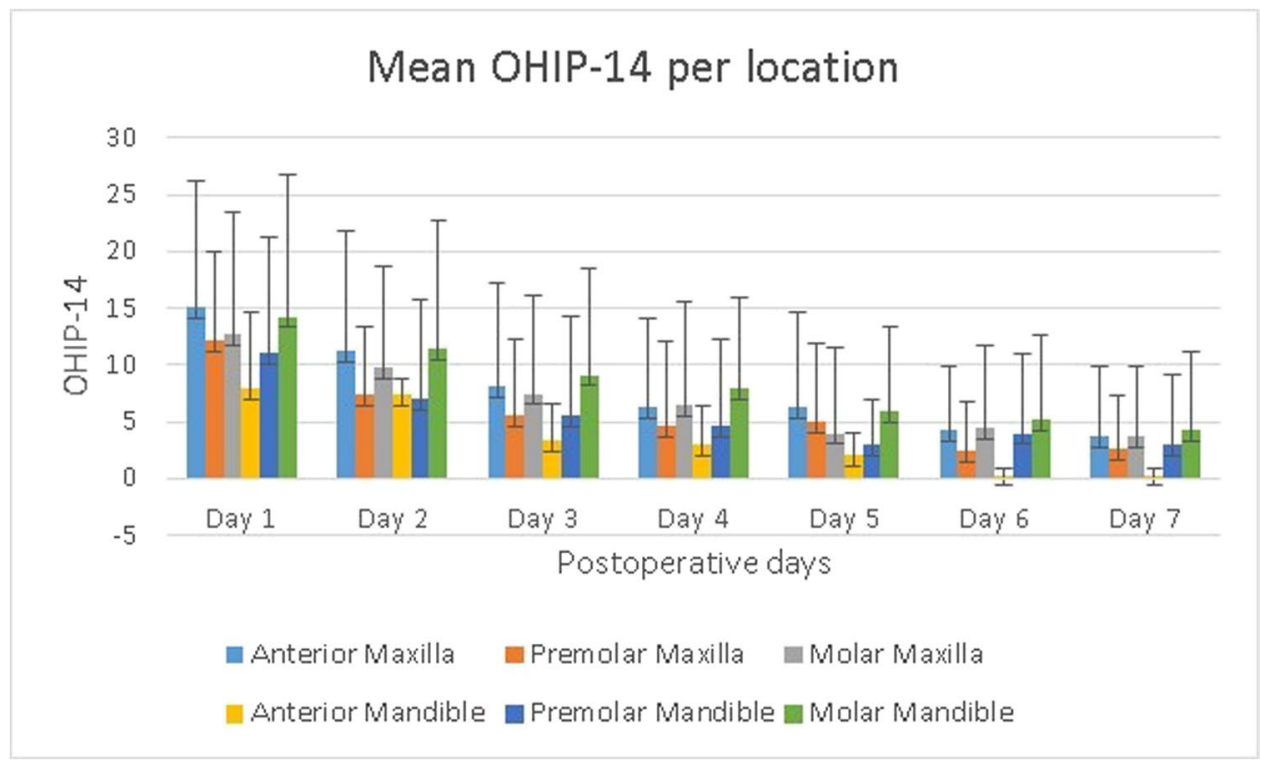

scores on the other days differed significantly from each other $(p<0.05)$.

Women and smokers experienced significantly more pain during the first 3 days. Younger patients had a higher pain score compared to older patients on the first postoperative day. We found no significant interaction effect during the first postoperative week for pain scores and ASA group, surgical flaps, location of teeth, or operation time. Comparing the second molar region with the other locations, we found no significant differences during the week for the NRS pain scores, or even during the first 3 days (day $1, p=0.30$; day $2, p=0.32$; day $3, p=0.29$ ). Figure 2 shows the pain scores versus the location of the operated teeth.

\section{Analgesic intake}

Repeated measures were used to determine mean scores over time for pain from postoperative days 1 to 7 . Repeated measures ANOVA was used to analyze mean analgesic intake each day during the first postoperative week (Table 3). We found a significant effect for the repeated measurements $(\mathrm{F}(6,127)=26.8, p<0.001)$. Subsequent pairwise comparisons show that the mean analgesic use decreased significantly throughout the week. Only the mean scores from days 4 and 5 and days 6 and 7 did not differ significantly $(p=1.00)$, whereas all of the mean scores on the other days differed significantly from each other $(p<0.05)$. We found no significant interaction effect during the first postoperative week for mean analgesic intake and gender, ASA group, smokers, surgical flaps, operation time, or location of teeth. Figure 3 shows the mean number of analgesic intake for the location of the operated teeth. On the first postoperative day, $14.3 \%$ of patients reported not using any analgesics. This percentage increased to $30.8 \%$ on day 2 and $42.1 \%$ on day 3 . On the seventh day, $23.3 \%$ of the patients used analgesics.

\section{Postoperative swelling, mouth opening, and chewing difficulties}

Tables 4 and 5 show the effect of periapical surgery on postoperative swelling, limitations in mouth opening, and chewing difficulties. Swelling was significantly different between genders on postoperative days 1 and 4 , with women reporting more swelling. On the first postoperative day, more swelling was reported in the patients with an ASA I classification.

A significant difference in mouth opening was found on days 2, 3, and 4 for teeth surgically treated in the lower jaw. Postoperative swelling persisted longer in mandibular locations, especially the molars, and was significant on days 5, 6 , and 7. Limitations in mouth opening were reported significantly more in females on the first postoperative day and in the ASA I group on the third postoperative day.

\section{Postoperative complications}

Seven $(5.3 \%)$ patients with a postoperative infection presented with increasing swelling at the surgical site on postoperative day 6 . The abscess was drained, followed by a 5 -day oral course of $500 \mathrm{mg}$ amoxicillin three times a day. The patients with a postoperative infection had a significantly higher OHIP-14 score on the fifth postoperative day and a significantly higher pain score on the sixth postoperative day, which corresponded with the day that the abscess was drained (Tables 1 and 2). 
Table 2 NRS pain scores for the 1st postoperative week

\begin{tabular}{|c|c|c|c|c|c|c|c|c|c|}
\hline Group & Sample & & Day 1 & Day 2 & Day 3 & Day 4 & Day 5 & Day 6 & Day 7 \\
\hline \multirow[t]{2}{*}{ Men } & \multirow[t]{2}{*}{54} & Mean & $2.50^{*}$ & $2.06^{*}$ & $1.72 *$ & 1.64 & 1.72 & 1.52 & 1.94 \\
\hline & & SD & 2.31 & 2.29 & 2.06 & 2.13 & 2.18 & 2.37 & 2.26 \\
\hline \multirow[t]{2}{*}{ Women } & \multirow[t]{2}{*}{79} & Mean & $3.75^{*}$ & $2.92 *$ & $2.48^{*}$ & 2.17 & 1.71 & 1.35 & 1.11 \\
\hline & & SD & 2.45 & 2.46 & 2.25 & 2.21 & 2.01 & 1.69 & 1.58 \\
\hline \multirow[t]{2}{*}{ ASA I } & \multirow[t]{2}{*}{88} & Mean & 3.40 & 2.60 & 2.23 & 2.06 & 1.80 & 1.53 & 1.24 \\
\hline & & SD & 2.45 & 2.40 & 2.13 & 2.24 & 2.12 & 2.09 & 1.99 \\
\hline \multirow[t]{2}{*}{ ASA II } & \multirow[t]{2}{*}{45} & Mean & 2.94 & 2.51 & 2.06 & 1.76 & 1.57 & 1.19 & 0.94 \\
\hline & & SD & 2.50 & 2.47 & 2.36 & 2.09 & 1.99 & 1.77 & 1.64 \\
\hline \multirow[t]{2}{*}{ Smokers } & \multirow[t]{2}{*}{17} & Mean & $4.76^{*}$ & $3.65^{*}$ & $3.24 *$ & 2.47 & 1.65 & 1.29 & 1.06 \\
\hline & & SD & 2.54 & 2.42 & 2.17 & 1.91 & 1.58 & 1.40 & 1.52 \\
\hline \multirow[t]{2}{*}{ Non-smokers } & \multirow[t]{2}{*}{116} & Mean & $3.03 *$ & $2.41 *$ & $2.02 *$ & 1.88 & 1.73 & 1.44 & 1.16 \\
\hline & & SD & 2.39 & 2.39 & 2.17 & 2.22 & 2.14 & 2.06 & 1.93 \\
\hline \multirow[t]{2}{*}{ Age $18-25$ yrs } & \multirow[t]{2}{*}{5} & Mean & $4.80^{*}$ & 3.40 & 3.00 & 3.00 & 1.20 & 1.00 & 0.70 \\
\hline & & SD & 1.92 & 1.34 & 1.87 & 2.55 & 1.10 & 1.22 & 1.10 \\
\hline \multirow[t]{2}{*}{ Age $26-45$ yrs } & \multirow[t]{2}{*}{45} & Mean & $3.70 *$ & 2.91 & 2.57 & 2.19 & 1.90 & 1.76 & 1.38 \\
\hline & & SD & 2.28 & 2.52 & 2.28 & 2.16 & 1.98 & 2.10 & 2.10 \\
\hline \multirow[t]{2}{*}{ Age $46-65$ yrs } & \multirow[t]{2}{*}{61} & Mean & $3.22 *$ & 2.62 & 2.14 & 1.88 & 1.69 & 1.30 & 1.16 \\
\hline & & SD & 2.71 & 2.54 & 2.29 & 2.23 & 2.15 & 1.87 & 1.91 \\
\hline \multirow[t]{2}{*}{ Age $>65$ yrs } & \multirow[t]{2}{*}{22} & Mean & $2.05^{*}$ & 1.55 & 1.27 & 1.45 & 1.55 & 1.14 & 0.73 \\
\hline & & SD & 1.81 & 1.79 & 1.55 & 2.04 & 2.30 & 2.21 & 1.39 \\
\hline \multirow[t]{2}{*}{ Postop infection } & \multirow[t]{2}{*}{7} & Mean & 2.29 & 2.14 & 2.14 & 2.29 & 3.00 & $2.86^{*}$ & 2.29 \\
\hline & & SD & 1.80 & 2.19 & 1.77 & 2.21 & 2.08 & 2.41 & 2.63 \\
\hline \multirow[t]{2}{*}{ No postop infection } & 126 & Mean & 3.30 & 2.60 & 2.17 & 1.94 & 1.65 & $1.34^{*}$ & 1.08 \\
\hline & & SD & 2.49 & 2.44 & 2.22 & 2.19 & 2.06 & 1.94 & 1.82 \\
\hline Quadr. flap & 63 & Mean & 3.52 & 2.71 & 2.42 & 2.06 & 1.81 & 1.47 & 1.20 \\
\hline & & SD & 2.55 & 2.71 & 2.51 & 2.31 & 2.16 & 2.09 & 2.07 \\
\hline Triang. flap & 60 & Mean & 2.78 & 2.30 & 1.97 & 1.80 & 1.59 & 1.34 & 1.09 \\
\hline & & SD & 2.32 & 2.09 & 1.78 & 2.10 & 2.05 & 1.96 & 1.76 \\
\hline Midlevel flap & 10 & Mean & 4.40 & 3.30 & 2.90 & 2.20 & 1.90 & 1.55 & 1.10 \\
\hline & & SD & 2.46 & 2.31 & 2.13 & 1.99 & 1.85 & 1.64 & 1.45 \\
\hline Surgery & & & & & & & & & \\
\hline$<20 \min$ & 63 & Mean & 3.51 & 2.81 & 2.17 & 2.02 & 1.97 & 1.64 & 1.24 \\
\hline & & SD & 2.60 & 2.47 & 2.17 & 2.23 & 2.25 & 2.22 & 1.85 \\
\hline $21-25 \min$ & 18 & Mean & 3.06 & 2.11 & 1.83 & 1.58 & 1.33 & 1.22 & 1.28 \\
\hline & & SD & 2.53 & 2.47 & 2.43 & 1.85 & 1.61 & 1.90 & 2.37 \\
\hline $26-30 \mathrm{~min}$ & 44 & Mean & 3.11 & 2.57 & 2.45 & 2.15 & 1.69 & 1.27 & 0.98 \\
\hline & & SD & 2.34 & 2.42 & 2.27 & 2.38 & 2.06 & 1.71 & 1.72 \\
\hline$>30 \mathrm{~min}$ & 8 & Mean & 2.38 & 1.75 & 1.38 & 1.25 & 0.75 & 0.88 & 1.00 \\
\hline & & SD & 2.00 & 1.83 & 1.19 & 1.39 & 1.39 & 1.99 & 2.07 \\
\hline Overall & 133 & Mean & 3.25 & 2.57 & 2.17 & 1.95 & 1.72 & 1.42 & 1.14 \\
\hline & & SD & 2.47 & 2.42 & 2.20 & 2.19 & 2.07 & 1.99 & 1.88 \\
\hline
\end{tabular}

quadr quadrangular; triang triangular; $S D$ standard deviation ${ }^{*} p<0.05$

\section{Discussion}

In the present study, we assessed how periapical surgery affects postoperative OHRQoL and found the greatest effect of periapical surgery on OHRQoL and NRS pain scores during the first postoperative day, gradually decreasing through the first postoperative week. Compared to earlier studies on postoperative OHRQoL and pain after third molar surgery, periapical surgery only had a mild to moderate effect during the first postoperative week [19-21]. This finding is supported by other studies that found maximal postoperative symptoms on days 1 to 3 , which then generally subsided [5, 
Fig. 2 Mean numeric rating scale (NRS) pain score per location during the 1st postoperative week. Error bars indicate SD

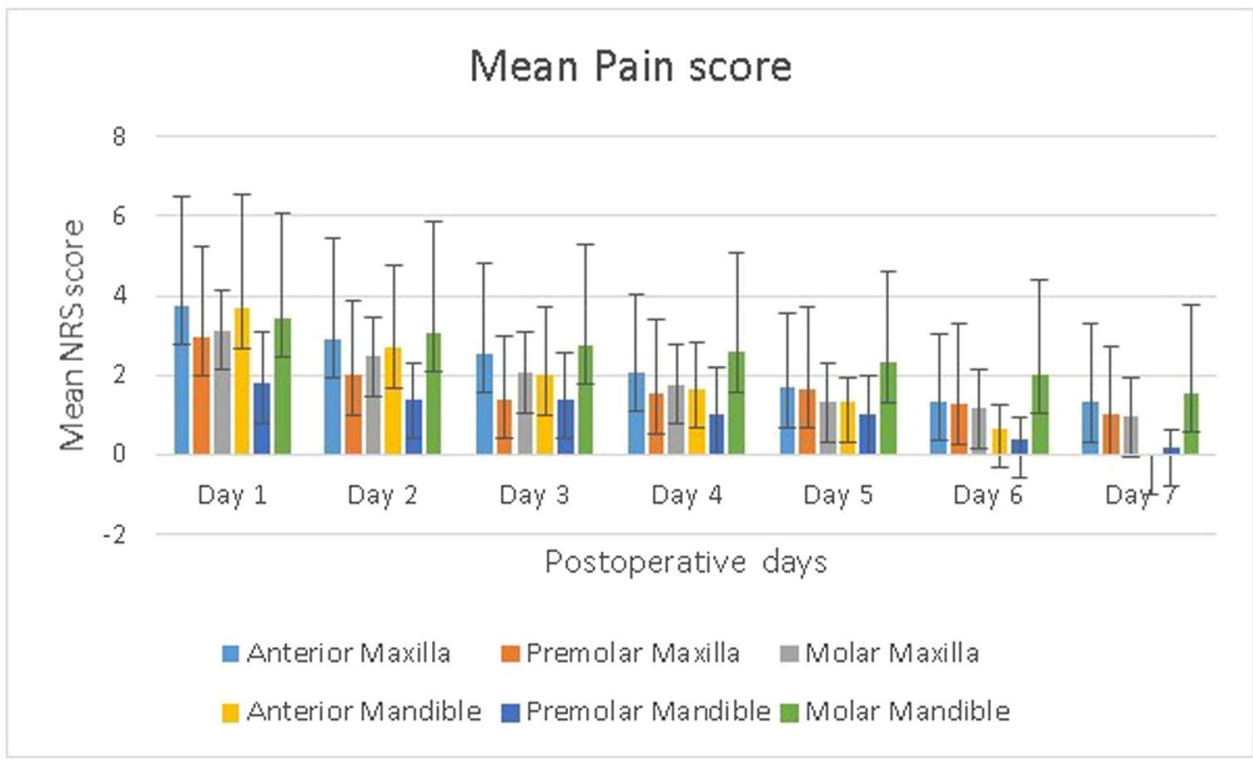

6]. In the present study, we found no significant differences in mean OHIP-14 scores between males and females.

Postoperative pain is not uncommon following periapical surgery, and is usually of short duration, with a maximum intensity either on the day of the surgical procedure or the next day $[3,7,9,14]$. In the present study, the mean NRS pain score was highest during the first 3 days. The mean NRS pain score was 3.25 (SD 2.47) on day 1, decreasing to 2.57 (SD 2.42) on day 2 and gradually decreasing through the week. Iqbal et al. [11] reported a mean pain score on day 1 of 3.17 (SD 2.03), and other studies have reported mean peak visual analog scale (VAS) scores of approximately 30 , which is comparable to the present study [3, 4]. Garcia et al. found the highest pain score on day 2 [10].

The postoperative mean pain score is influenced by the analgesics taken by patients and, as such, does not truly reflect the real pain caused by the surgery. To obtain a real measurement of the pain after periapical surgery, patients should refrain from taking analgesics; however, as pointed out by Seymour et al., this approach would be unethical [3].

The NRS pain score exhibited a significant gender difference in the first 3 days, with women experiencing more pain, but this did not affect the OHRQoL. The mean differences in OHIP-14 score were not significantly different between males and females; however, the slightly higher pain with less impact on OHRQoL observed in women may be explained by women being better at managing pain than men [22]. Therefore, the OHIP-14 score may reflect the notion that pain did not hinder day-to-day life in women as much as it did in men [22]. Interestingly, Penarrocha et al. [8] found higher pain scores for males after periapical surgery until the third postoperative day, whereas other studies reported no significant differences in pain scores between males and females after apical surgery $[3,5,6]$.

In the present study, the younger age group $(<25$ years $)$ experienced a greater effect of periapical surgery during the first 2 days and more pain during the first postoperative day. This finding is in contrast to other studies that did not find any significant effect of age on postoperative symptoms after periapical surgery $[3,5,6,9,10]$. However, Iqbal et al. found more postoperative discomfort in younger patients [11].

In the present study, ibuprofen was used as an analgesic in younger patients and paracetamol in the ASA II group and older patients. No significant differences were found in the use of analgesics between gender, age groups, smokers or non-smokers, flap design, or location. In the present study, $85.7 \%$ of the patients reported using analgesics on the first postoperative day. This decreased during the week and, on the seventh postoperative day, $23.3 \%$ of the patients used analgesics. Earlier studies reported that $63-67 \%$ of the patients took analgesics, which meant that some patients did not take them even though pain was reported $[4,7]$.

Surgical operation time, ASA classification, and flap design did not significantly impact OHRQoL and NRS pain scores during the first postoperative week. Seymour et al. also failed to find a correlation between operating time and postoperative pain. Studies have reported great variety in operation time, from a mean of 25 min to a time of $140 \mathrm{~min}$ for a single-rooted tooth [3, 8, 12, 14]. However, no significant correlation between operation time and postoperative pain and swelling were found. Penarrocha et al. found that trapezoidal flaps caused greater pain than triangular flaps, particularly in the first 2 days [8].

We found that smokers had a significantly higher OHIP14 score on the first postoperative day than non-smokers. 
Table 3 Analgesic intake during the 1st postoperative week

\begin{tabular}{|c|c|c|c|c|c|c|c|c|c|}
\hline Group & Sample & & Day 1 & Day 2 & Day 3 & Day 4 & Day 5 & Day 6 & Day 7 \\
\hline \multirow[t]{2}{*}{ Men } & \multirow[t]{2}{*}{54} & Mean & 2.24 & 1.58 & 1.25 & 0.87 & 0.85 & 0.77 & 0.62 \\
\hline & & SD & 1.82 & 1.74 & 1.53 & 1.41 & 1.45 & 1.64 & 1.51 \\
\hline \multirow[t]{2}{*}{ Women } & \multirow[t]{2}{*}{79} & Mean & 2.70 & 1.96 & 1.79 & 1.40 & 1.09 & 0.75 & 0.68 \\
\hline & & $\mathrm{SD}$ & 1.80 & 1.88 & 2.04 & 2.07 & 1.72 & 1.48 & 1.45 \\
\hline \multirow[t]{2}{*}{ Smokers } & \multirow[t]{2}{*}{17} & Mean & 2.53 & 2.47 & 2.12 & 1.12 & 0.47 & 0.47 & 0.53 \\
\hline & & SD & 1.70 & 2.15 & 1.93 & 1.69 & 1.18 & 1.18 & 1.50 \\
\hline \multirow[t]{2}{*}{ Non-smokers } & \multirow[t]{2}{*}{116} & Mean & 2.51 & 1.76 & 1.50 & 1.20 & 1.07 & 0.80 & 0.68 \\
\hline & & SD & 1.84 & 1.83 & 1.85 & 1.88 & 1.64 & 1.58 & 1.47 \\
\hline \multirow[t]{2}{*}{ ASA I } & \multirow[t]{2}{*}{88} & Mean & 2.40 & 1.85 & 1.61 & 1.27 & 1.03 & 0.86 & 0.69 \\
\hline & & SD & 1.77 & 1.80 & 1.89 & 1.94 & 1.56 & 1.56 & 1.38 \\
\hline \multirow[t]{2}{*}{ ASA II } & \multirow[t]{2}{*}{45} & Mean & 2.73 & 1.84 & 1.49 & 1.02 & 0.93 & 0.58 & 0.59 \\
\hline & & SD & 1.90 & 2.04 & 1.83 & 1.67 & 1.68 & 1.48 & 1.64 \\
\hline \multirow[t]{2}{*}{ Age $18-25$ yrs } & \multirow[t]{2}{*}{5} & Mean & 2.60 & 2.00 & 2.50 & 2.50 & 0.50 & 0.10 & 1.20 \\
\hline & & SD & 1.95 & 1.00 & 3.32 & 4.24 & 0.87 & 0.22 & 2.68 \\
\hline \multirow[t]{2}{*}{ Age $26-45$ yrs } & \multirow[t]{2}{*}{45} & Mean & 2.53 & 2.02 & 1.75 & 1.20 & 1.09 & 0.86 & 0.56 \\
\hline & & SD & 1.74 & 1.95 & 2.05 & 1.79 & 1.80 & 1.65 & 1.30 \\
\hline \multirow[t]{2}{*}{ Age $46-65$ yrs } & \multirow[t]{2}{*}{61} & Mean & 2.36 & 1.82 & 1.34 & 0.93 & 0.82 & 0.75 & 0.66 \\
\hline & & SD & 1.84 & 1.94 & 1.60 & 1.58 & 1.45 & 1.61 & 1.57 \\
\hline \multirow[t]{2}{*}{ Age $>65$ yrs } & \multirow[t]{2}{*}{22} & Mean & 2.86 & 1.54 & 1.64 & 1.54 & 1.41 & 0.73 & 0.73 \\
\hline & & SD & 1.96 & 1.79 & 1.81 & 1.87 & 1.66 & 1.28 & 1.24 \\
\hline \multirow[t]{2}{*}{ Infection } & \multirow[t]{2}{*}{7} & Mean & 2.71 & 2.29 & 2.00 & 1.43 & 1.14 & 1.29 & 1.00 \\
\hline & & SD & 2.21 & 1.60 & 1.63 & 1.40 & 0.90 & 1.50 & 1.73 \\
\hline \multirow[t]{2}{*}{ No infection } & 126 & Mean & 2.50 & 1.82 & 1.55 & 1.17 & 0.99 & 0.73 & 0.64 \\
\hline & & SD & 1.80 & 1.90 & 1.88 & 1.87 & 1.63 & 1.54 & 1.46 \\
\hline Quadr. flap & 63 & Mean & 2.48 & 1.79 & 1.55 & 1.20 & 0.93 & 0.73 & 0.65 \\
\hline & & SD & 1.87 & 1.92 & 2.13 & 2.04 & 1.57 & 1.56 & 1.45 \\
\hline Triang. flap & 60 & Mean & 2.53 & 1.92 & 1.55 & 1.22 & 1.10 & 0.85 & 0.70 \\
\hline & & SD & 1.86 & 1.95 & 1.62 & 1.70 & 1.65 & 1.59 & 1.55 \\
\hline Midlevel flap & 10 & Mean & 2.60 & 1.80 & 1.70 & 0.80 & 0.70 & 0.30 & 0.30 \\
\hline & & SD & 1.26 & 1.23 & 1.57 & 1.48 & 1.49 & 0.95 & 0.95 \\
\hline Surgery & & & & & & & & & \\
\hline$<20 \min$ & 63 & Mean & 2.56 & 1.86 & 1.59 & 1.16 & 1.03 & 0.81 & 0.67 \\
\hline & & SD & 1.94 & 2.01 & 1.81 & 1.77 & 1.68 & 1.64 & 1.60 \\
\hline $21-25 \min$ & 18 & Mean & 2.17 & 1.39 & 0.94 & 0.61 & 0.56 & 0.33 & 0.67 \\
\hline & & SD & 1.34 & 1.20 & 1.30 & 0.98 & 0.92 & 0.69 & 1.53 \\
\hline $26-30 \mathrm{~min}$ & 44 & Mean & 2.66 & 2.14 & 1.89 & 1.48 & 1.13 & 0.89 & 0.61 \\
\hline & & SD & 1.92 & 1.98 & 2.17 & 2.27 & 1.77 & 1.70 & 1.32 \\
\hline$>30 \mathrm{~min}$ & 8 & Mean & 2.13 & 1.25 & 0.94 & 0.94 & 0.81 & 0.56 & 0.63 \\
\hline & & SD & 1.82 & 1.16 & 1.15 & 1.02 & 0.84 & 0.90 & 1.19 \\
\hline Overall & 133 & Mean & 2.51 & 1.85 & 1.56 & 1.18 & 0.99 & 0.76 & 0.65 \\
\hline & & SD & 1.82 & 1.87 & 1.86 & 1.84 & 1.59 & 1.53 & 1.46 \\
\hline
\end{tabular}

quadr quadrangular; triang triangular; $S D$ standard deviation
In addition, smokers experienced significantly more pain during the first 3 days. Garcia et al. also found that smokers experienced greater pain throughout almost the entire first postoperative week [10].

In the present study, the operation site had no significant influence on postoperative OHRQoL or pain. This finding is in agreement with other studies [5, 6, 8, 12, 14]. One would expect more postoperative discomfort after periapical surgery in second molars, but we found no significant effect in regard to the postoperative OHRQoL or pain scores. Other studies have found greater pain after periapical surgery of maxillary anterior teeth [11], molars [9], or the lower incisors and canines [8].

Swelling is common following surgical periapical treatment. In the present study, swelling was significantly different between genders on postoperative days 1 and 4, with 
Fig. 3 Mean analgesic consumption score per location during the 1st postoperative week. Error bars indicate SD

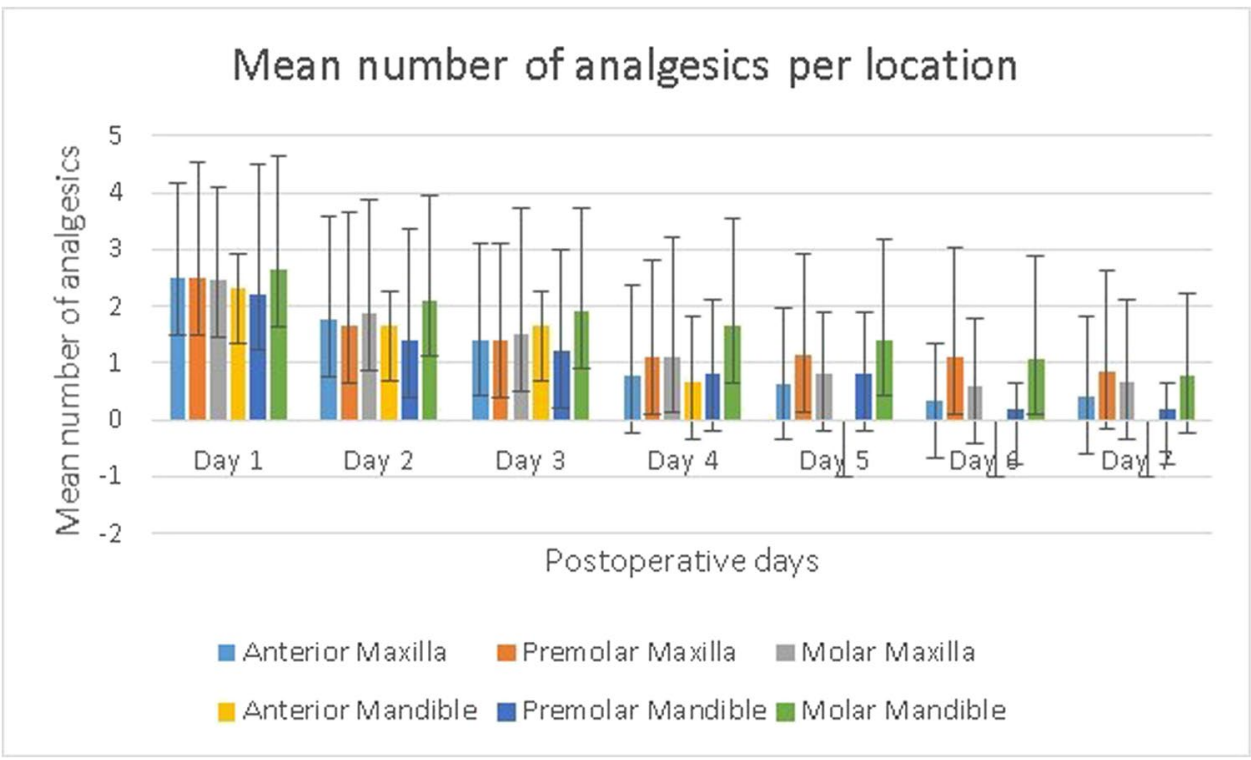

women reporting more swelling. Postoperative swelling persisted longer in mandibular locations and was significant on days 5,6 , and 7. Previous reports found that the maximum swelling is experienced on the first postoperative day $[4,11]$ and patients were more likely to experience swelling than pain [11]. Garcia et al. [10] reported that $40.3 \%$ of their patients had no or only mild postoperative swelling on the first postoperative day, whereas Tsesis et al. [5] found that $64.7 \%$ of their patients did not report any swelling; however, patients in that study received dexamethasone, which influences the postoperative outcome with regard to swelling. We found that limitations in mouth opening were significantly more common in females on the first postoperative day and in the ASA I group on the third postoperative day. A significant difference in mouth opening was also found on days 2 , 3 , and 4 for teeth surgically treated in the lower jaw. Swelling, chewing, and phonetic impairment were the worst 1 and 2 days after surgery $[8,14]$.

Several earlier studies used some form of antibiotic prophylaxis for periapical surgical procedures $[9,11,12,17]$. In the present study, however, no antibiotics were prescribed. A previous randomized double-blind placebo-controlled trial comparing oral placebo and a preoperative dose of $600 \mathrm{mg}$ clindamycin in 256 patients [23] reported an infection rate

Table 4 Number of patients with select complications during the 1st postoperative week

\begin{tabular}{|c|c|c|c|c|c|c|c|c|c|c|c|c|c|c|c|c|c|c|c|c|c|c|}
\hline \multirow[t]{2}{*}{ Group } & \multirow[t]{2}{*}{ Sample } & \multicolumn{3}{|c|}{ Day 1} & \multicolumn{3}{|c|}{ Day 2} & \multicolumn{3}{|c|}{ Day 3} & \multicolumn{3}{|c|}{ Day 4} & \multicolumn{3}{|c|}{ Day 5} & \multicolumn{3}{|c|}{ Day 6} & \multicolumn{3}{|c|}{ Day 7} \\
\hline & & S & M & $\mathrm{C}$ & S & $\mathrm{M}$ & $\mathrm{C}$ & S & M & $\mathrm{C}$ & S & $\mathrm{M}$ & $\mathrm{C}$ & S & $\mathrm{M}$ & $\mathrm{C}$ & S & $\mathrm{M}$ & $\mathrm{C}$ & S & $\mathrm{M}$ & $\mathrm{C}$ \\
\hline Male & 54 & $36^{*}$ & $27 *$ & 29 & 38 & 20 & $23 *$ & 31 & 16 & $17 *$ & $22 *$ & 16 & 15 & 20 & 11 & 11 & 16 & 7 & 12 & 13 & 7 & \\
\hline Female & 79 & $66^{*}$ & $52 *$ & 54 & 66 & 37 & $52 *$ & 57 & 35 & $42 *$ & $52 *$ & 25 & 32 & 36 & 21 & 28 & 31 & 17 & 20 & 24 & 13 & 1 \\
\hline ASA I & 88 & $73 *$ & 57 & 57 & 72 & 42 & 51 & 61 & $39^{*}$ & 43 & 50 & 30 & 35 & 40 & 24 & 30 & 34 & 17 & 25 & 26 & 14 & 2 \\
\hline ASA II & 45 & $29 *$ & 22 & 26 & 32 & 15 & 24 & 27 & $12^{*}$ & 16 & 24 & 11 & 12 & 16 & 8 & 9 & 13 & 7 & 7 & 11 & 6 & 7 \\
\hline mokers & 17 & 1 & 11 & 13 & 15 & 8 & 12 & 14 & 8 & $\varepsilon$ & 12 & 6 & 6 & 8 & 4 & 6 & 7 & 5 & 4 & 5 & 3 & 4 \\
\hline Jon-smok & 116 & 88 & 68 & 70 & 89 & 49 & 63 & 74 & 43 & 51 & 62 & 35 & 41 & 48 & 28 & 33 & 40 & 19 & 28 & 32 & 17 & 2 \\
\hline Quadr flap & 63 & 52 & 38 & 41 & 51 & 29 & 37 & 46 & 26 & 30 & 37 & 23 & 26 & 27 & 18 & 19 & 26 & 14 & 14 & 22 & 11 & 1 \\
\hline Trial & 60 & 43 & 34 & 37 & 46 & 24 & 33 & 36 & 21 & 26 & 33 & 15 & 18 & 25 & 11 & 17 & 18 & 8 & 16 & 12 & 6 & 1 \\
\hline Midlev flap & 10 & 7 & 7 & 5 & 7 & 4 & 5 & 6 & 4 & 3 & 4 & 3 & 3 & 4 & 3 & 3 & 3 & 2 & 2 & 3 & 3 & 1 \\
\hline $\mathrm{OT}<20 \mathrm{~min}$ & 63 & 45 & 36 & 41 & 46 & 25 & 35 & 36 & 19 & 25 & 32 & 18 & 21 & 26 & 12 & 17 & 20 & 11 & 17 & 13 & 10 & 15 \\
\hline OT $20-25 \mathrm{~min}$ & 18 & 16 & 11 & 11 & 13 & 5 & 8 & 10 & 3 & 8 & 8 & 3 & 6 & 3 & 2 & 5 & 3 & 2 & 4 & 3 & 1 & 4 \\
\hline OT 26-30 Min & 44 & 34 & 28 & 25 & 38 & 25 & 28 & 36 & 25 & 22 & 28 & 19 & 18 & 23 & 16 & 15 & 20 & 10 & 10 & 19 & 8 & 8 \\
\hline $\mathrm{OT}>30 \mathrm{Min}$ & 8 & 7 & 4 & 6 & 7 & 2 & 4 & 6 & 4 & 4 & 6 & 1 & 2 & 4 & 2 & 2 & 4 & 1 & 1 & 2 & 1 & 1 \\
\hline Total & 133 & 102 & 79 & 83 & 104 & 57 & 75 & 88 & 51 & 59 & 74 & 41 & 47 & 56 & 32 & 39 & 47 & 24 & 32 & 37 & 20 & 28 \\
\hline
\end{tabular}

$S$ swelling; $M$ limited mouth opening; $C$ chewing difficulties; $O T$ operation time; quadr quadrangular; triang triangular ${ }^{*} p<0.05$ 
Table 5 Number of patients experiencing select complications during the 1st postoperative week per location

\begin{tabular}{|c|c|c|c|c|c|c|c|c|c|c|c|c|c|c|c|c|c|c|c|c|c|c|}
\hline \multirow[t]{2}{*}{ Location } & \multirow[t]{2}{*}{ Sample } & \multicolumn{3}{|c|}{ Day 1} & \multicolumn{3}{|c|}{ Day 2} & \multicolumn{3}{|c|}{ Day 3} & \multicolumn{3}{|c|}{ Day 4} & \multicolumn{3}{|c|}{ Day 5} & \multicolumn{3}{|c|}{ Day 6} & \multicolumn{3}{|c|}{ Day 7} \\
\hline & & $S$ & M & $\mathrm{C}$ & $S$ & M & $\mathrm{C}$ & S & M & $\mathrm{C}$ & $\mathrm{S}$ & M & $\mathrm{C}$ & $\mathrm{S}$ & M & $\mathrm{C}$ & $\mathrm{S}$ & M & $\mathrm{C}$ & $\mathrm{S}$ & M & $\mathrm{C}$ \\
\hline Anterior maxilla & 22 & 15 & 14 & 14 & 16 & $7 *$ & 10 & 12 & $4^{*}$ & 6 & 9 & $4^{*}$ & 6 & $6^{*}$ & 2 & 6 & $3 *$ & 1 & 3 & $2 *$ & 1 & 2 \\
\hline Premolar maxilla & 29 & 22 & 19 & 16 & 24 & $11^{*}$ & 15 & 18 & $8^{*}$ & 11 & 15 & $8^{*}$ & 9 & $9 *$ & 5 & 7 & $9 *$ & 4 & 8 & $7 *$ & 3 & 8 \\
\hline Molar maxilla & 37 & 26 & 24 & 19 & 24 & $11^{*}$ & 21 & 23 & $13^{*}$ & 15 & 17 & $9 *$ & 13 & $12 *$ & 11 & 11 & $12 *$ & 7 & 9 & $7 *$ & 6 & 9 \\
\hline Anterior mandible & 3 & 3 & 1 & 3 & 3 & $3 *$ & 2 & 3 & $3 *$ & 2 & 3 & $3 *$ & 2 & $3 *$ & 2 & 1 & $2 *$ & 2 & 1 & $2 *$ & 2 & 1 \\
\hline Premolar mandible & 5 & 5 & 3 & 3 & 4 & $3^{*}$ & 3 & 3 & $2 *$ & 3 & 3 & $2 *$ & 3 & $1 *$ & 1 & 2 & $1 *$ & 1 & 2 & $0 *$ & 0 & 2 \\
\hline Molar mandible & 37 & 31 & 22 & 24 & 33 & $22 *$ & 24 & 29 & $21^{*}$ & 22 & 27 & $15^{*}$ & 14 & $25 *$ & 11 & 12 & $20 *$ & 9 & 9 & $19 *$ & 8 & 6 \\
\hline Total & 133 & 102 & 83 & 79 & 104 & 57 & 75 & 88 & 51 & 59 & 74 & 41 & 47 & $56^{*}$ & 32 & 39 & 47 & 24 & 32 & 37 & 20 & 28 \\
\hline
\end{tabular}

$S$ swelling; $M$ limited mouth opening; $C$ chewing difficulties

*Significant $<0.05$

of $1.6 \%$ in the antibiotic prophylaxis group versus $3.2 \%$ in the placebo group. In the present study, 7 (5.3\%) cases of postoperative infection occurred, which were treated with drainage and a 5-day course of amoxicillin. Patients with a postoperative infection had a significantly higher OHIP-14 score on day 5 and more pain on day 6 .

This study has some limitations. First, only asymptomatic cases were included; therefore, no conclusions can be drawn about the impact on OHRQoL in cases of acute periapical surgery. Second, we did not use an operating microscope in the periapical procedure. An operating microscope is used for optimal identification of root canals, fractures, and isthmuses [17], and some studies have reported that the use of microsurgical techniques is associated with less postoperative pain $[1,5,6]$. Magnification was used in the present study, but the $\times 5$ magnification with the surgical loupes does not compare to visualization of 16 to 32 times as with the microscope. Although an earlier study did find that patients undergoing periapical surgery using a surgical microscope recovered sooner with respect to pain, no significant difference was found in postoperative swelling [1]. A disadvantage of performing periapical surgery with a microscope is that the procedure takes twice as long. Tsesis et al. [5] reported an average operating time of $20 \mathrm{~min}$ for periapical surgery without a microscope versus $40 \mathrm{~min}$ for periapical surgery using a microscope [6]. Moreover, in that study, the patients from the group operated on using a microscope experienced more difficulty in mouth opening, mastication, and the ability to speak during the first 2 days after surgery. In addition, no significant differences in pain were observed in those first 2 days. The differences in pain became clear starting with the fourth postoperative day, but the mean pain scores were $\sim 2$ on a 5-point scale. In contrast, in the present study, the mean pain scores were $\leq 2$ on an 11-point NRS.

Another limitation of the present study is that, although the OHIP-14 is a reliable and validated tool to measure OHRQoL, data acquired from the patients are self-reported. The usual disadvantage with questionnaires is that data acquisition is subjective, and the data cannot be controlled. As such, some bias may be present [19, 24]. Facial swelling as such was not measured but reported on the OHIP-14 questionnaire, so the OHIP-14 scores were used to subjectively assess postoperative swelling. Objective methods for assessing the degree of postoperative swelling are more accurate than the estimations made by patients themselves, but as stated by Happonen et al. [25], there is no real objective way to assess the degree of intraoral swelling, which is experienced by the patients as being at least as unpleasant as extraoral swelling. Moreover, the amount of postoperative swelling is inter-individually different and the absence of a control group in the present study makes it difficult to draw a significant conclusion.

\section{Conclusions}

We identified a low incidence of postoperative pain and reduced OHRQoL following periapical surgical treatment. The postoperative reduction in OHRQoL and pain were of short duration, with maximum intensity in the early postoperative period and decreasing with time.

\section{Declarations}

Ethical approval All procedures performed in studies involving human participants were in accordance with the ethical standards of the institutional and/or national research committee and with the 1964 Helsinki declaration and its later amendments or comparable ethical standards.

Informed consent Informed consent was obtained from all individual participants included in the study.

Conflict of interest The authors declare no competing interests. 
Open Access This article is licensed under a Creative Commons Attribution 4.0 International License, which permits use, sharing, adaptation, distribution and reproduction in any medium or format, as long as you give appropriate credit to the original author(s) and the source, provide a link to the Creative Commons licence, and indicate if changes were made. The images or other third party material in this article are included in the article's Creative Commons licence, unless indicated otherwise in a credit line to the material. If material is not included in the article's Creative Commons licence and your intended use is not permitted by statutory regulation or exceeds the permitted use, you will need to obtain permission directly from the copyright holder. To view a copy of this licence, visit http://creativecommons.org/licenses/by/4.0/.

\section{References}

1. Pecora G, Andreana S (1993) Use of dental operating microscope in endodontic surgery. Oral Surg Oral Med Oral Pathol 75:751-758

2. Şimşek-Kaya G, Saruhan N, Yapıcı-Yavuz G, Ertaş Ü (2018) A decision analysis for periapical surgery: retrospective study. J Clin Exp Dent 10:e914-e920

3. Seymour RA, Meechan JG, Blair GS (1986) Postoperative pain after apicoectomy. A clinical investigation. Int Endod J 19:242-247

4. Kvist T, Reit C (2000) Postoperative discomfort associated with surgical and nonsurgical endodontic retreatment. Endod Dent Traumatol 16:71-74

5. Tsesis I, Fuss Z, Lin S, Tilinger G, Peled M (2003) Analysis of postoperative symptoms following surgical endodontic treatment. Quintessence Int 34:756-760

6. Tsesis I, Shoshani Y, Givol N, Yahalom R, Fuss Z, Taicher S (2005) Comparison of quality of life after surgical endodontic treatment using two techniques: a prospective study. Oral Surg Oral Med Oral Pathol Oral Radiol Endod 99:367-371

7. Chong BS, Pitt Ford TR (2005) Postoperative pain after root-end resection and filling. Oral Surg Oral Med Oral Pathol Oral Radiol Endod 100:762-766

8. Penarrocha M, Garcia B, Marti E, Balaguer J (2006) Pain and inflammation after periapical surgery in 60 patients. J Oral Maxillofac Surg 64:429-433

9. Lin S, Levin L, Emodi O, Abu El-Naaj I, Peled M (2006) Etodolac versus dexamethasone effect in reduction of postoperative symptoms following surgical endodontic treatment: a double-blind study. Oral Surg Oral Med Oral Pathol Oral Radiol Endod 101:814-817

10. García B, Penarrocha M, Martí E, Gay-Escodad C, von Arx T (2007) Pain and swelling after periapical surgery related to oral hygiene and smoking. Oral Surg Oral Med Oral Pathol Oral Radiol Endod 104:271-276

11. Iqbal MK, Kratchman SI, Guess GM, Karabucak B, Kim S (2007) Microscopic periradicular surgery: perioperative predictors for postoperative clinical outcomes and quality of life assessment. J Endod 33:239-244

12. Christiansen R, Kirkevang LL, Hørsted-Bindslev P, Wenzel A (2008) Patient discomfort following periapical surgery. Oral Surg Oral Med Oral Pathol Oral Radiol Endod 105:245-250
13. García B, Larrazabal C, Peñarrocha M, Peñarrocha M (2008) Pain and swelling in periapical surgery. A literature update. Med Oral Patol Oral Cir Bucal 13:E726-729

14. Del Fabbro M, Taschieri S, Weinstein R (2009) Quality of life after microscopic periradicular surgery using two different incision techniques: a randomized clinical study. Int Endod J 42:360-367

15. Del Fabbro M, Ceresoli V, Lolato A, Taschieri S (2012) Effect of platelet concentrate on quality of life after periradicular surgery: a randomized clinical study. J Endod 38:733-739

16. Kan E, Coelho MS, Reside J, Card SJ, Tawil PZ (2016) Periapical microsurgery: the effects of locally injected dexamethasone on pain, swelling, bruising, and wound healing. J Endod 42:1608-1612

17. Meschi N, Fieuws S, Vanhoenacker A, Strijbos O, Van der Veken D, Politis C, Lambrechts P (2018) Root-end surgery with leucocyte- and platelet-rich fibrin and an occlusive membrane: a randomized controlled clinical trial on patients' quality of life. Clin Oral Investig 22:2401-2411

18. Zuolo ML, Ferreira MO, Gutmann JL (2000) Prognosis in periradicular surgery: a clinical prospective study. Int Endod J 33:91-98

19. Tuk JG, Lindeboom JA, Sana F, van Wijk AJ, Milstein DMJ (2019) Alveolar iodine tampon packing reduces postoperative morbidity after third molar surgery. J Oral Maxillofac Surg 77:2401-2411

20. van Wijk AJ, Kieffer JM, Lindeboom JA (2009) Effect of third molar surgery on oral health-related quality of life in the first postoperative week using Dutch version of Oral Health Impact Profile-14. J Oral Maxillofac Surg 67:1026-1031

21. Kieffer JM, van Wijk AJ, Ho JP, Lindeboom JA (2012) The internal responsiveness of the Oral Health Impact Profile-14 to detect differences in clinical parameters related to surgical third molar removal. Qual Life Res 21:1241-1247

22. Fillingim RB, King CD, Ribeiro-Dasilva MC, Rahim-Williams B, Riley JL 3rd (2009) Sex, gender, and pain: a review of recent clinical and experimental findings. J Pain 10:447-485

23. Lindeboom JA, Frenken JW, Valkenburg P, van den Akker HP (2005) The role of preoperative prophylactic antibiotic administration in periapical endodontic surgery: a randomized, prospective double-blind placebo-controlled study. Int Endod J 38:877-881

24. Lindeboom JA, Tuk JG, Möllenkamp P, van Wijk AJ (2020) Alveolar iodine tampon packing after impacted third molar surgery improves oral health-related quality of life and postoperative sequela: a randomized study. Oral Maxillofac Surg. https://doi. org/10.1007/s10006-020-00898-9

25. Happonen RP, Bäckstrom AC, Ylipaavalniemi P (1990) Prophylactic use of phenoxymethylpenicillin and tinidazole in mandibular third molar surgery, a comparative placebo controlled clinical trial. Br J Oral Maxillofac Surg 28:12-15

Publisher's Note Springer Nature remains neutral with regard to jurisdictional claims in published maps and institutional affiliations. 